\title{
The cost of dishonesty
}

\section{HILDEGUNN VILJUGREIN}

Department of Biology, Division of Zoology, University of Oslo, P.O. Box 1050, Blindern, N-0316 Oslo, Norway (hildegvi@bio.uio.no)

\section{SUMMARY}

The handicap principle states that stable biological signals must be honest and costly to produce. The cost of the signal should reflect the true quality of the signaller. Here, it is argued that honest signalling may be maintained although the used signals are not handicaps. A game theoretic model in the form of a game of signalling is presented: all the existing evolutionarily stable strategies (ESSs) are found. Honest and cheap signalling of male quality is shown to be evolutionarily stable if females divorce the mate if it turns out that he has cheated about his quality. However, for this ESS to apply, the cost of lost time must not be too great. The stability of the honest signalling is based on deceivers being prevented from spreading in the population because they suffer from a cost of divorce. Under some fairly strict conditions, a mixed polymorphism of dishonesty and honesty represents another possible ESS.

\section{INTRODUCTION}

Zahavi $(1975,1977,1987)$ argued that when there are conflicts of interest, signalling systems will favour the evolution of honest but costly signals that accurately reflect the fighting ability, or other qualities, of the sender. Later, this idea was supported by formal models (Pomiankowsky 1987a,b; Grafen 1990; Godfray 1991, 1995; Maynard Smith 1991; Johnstone \& Grafen 1992a,b, 1993; Pagel 1993; Vega-Redondo \& Hasson 1993; Johnstone 1994; Yachi 1995). Contrary to these models and Zahavi's handicap principle, Dawkins \& Guilford (1991) argued that where the costs of fully assessing a signaller are high and the value of the extra information gained is low, it will pay receivers to settle for cheaper, but less reliable indicators of quality.

There are circumstances in which cost-free signals can be both reliable and evolutionarily stable (Maynard Smith 1994; Krakauer \& Pagel 1995; Wedekind 1994). Maynard Smith (1994) found that cost-free signalling can be stable even if there exists a conflict of interest about the outcome of a contest for some proportion of the population, provided that this proportion is not too large. Taking spatial constraints on the interactions between signallers and receivers into consideration, Krakauer \& Pagel (1995) demonstrated that honest signalling can be favoured even in the absence of costs. However, we still do not know if these situations are realistic or how widespread costfree signalling is likely to be in nature.

Here, I propose a new hypothesis for maintaining honest and cheap display signals given by males in a population in connection with mate choice. Honest and cost-free display signals by males may evolve and be maintained by females abandoning deceivers after mating. A divorce represents a cost for males because they lose energy and time, which could have been used to attract other potential mates. Staying with a female would incur costs due to, for instance, mate guarding (Birkhead \& Møller 1992). If the female then divorces the male, there would be no benefits to outweigh this loss of energy.

The time spent prospecting for a mate is probably one of the major costs of female mate choice (e.g. Janetos 1980; Parker 1983; Andersson 1994; Sullivan 1994). My suggestion is that honest and cheap signals of quality by males may be favoured by female preferences because the female's cost of time will be reduced. I present a game theory model in the form of a game of signalling (e.g. Kreps 1990), and analyse whether such a system could make honest signalling an evolutionarily stable strategy. By this approach, honest and cheap signalling of male quality is shown to be evolutionarily stable if females reject males signalling that they are of low quality and only mate with males signalling that they are of high quality, and also divorce the mate if it turns out that he has cheated about his quality. Females should divorce a low-quality male if they have a chance to obtain a new mate of high quality. This hypothesis is based upon the critical assumption that males unintentionally would reveal their true quality, but that it takes time for females to acquire this information. The stability of the honest signalling is dependent on the female's cost of divorce being not too great, i.e. the female competition is not too strong.

\section{A SIGNAL GAME MODEL}

\section{(a) Model structure}

Let males have the option of displaying two kinds of signals to females: high-quality signal $(\mathrm{H})$ or low- 


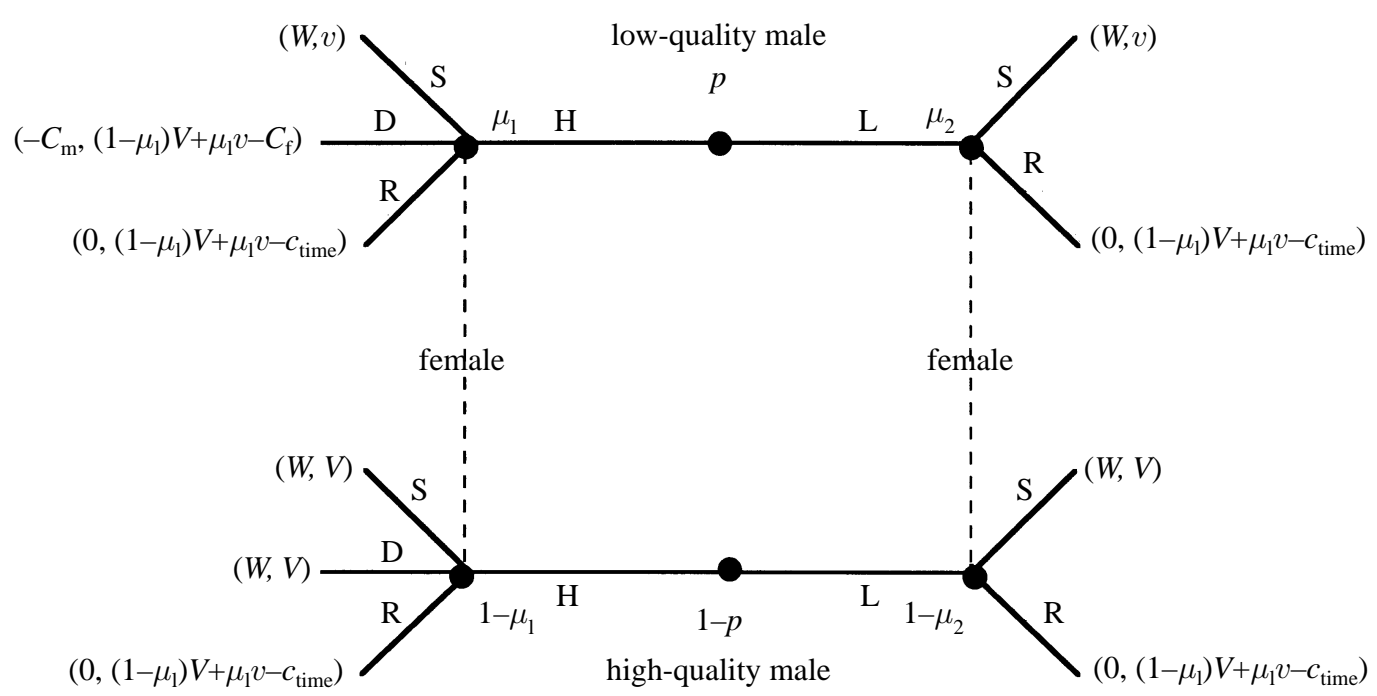

Figure 1. The basic game tree. A male is of poor quality with probability $p$ and of high quality with probability $1-p$. The branches leading from the male nodes correspond to a male's choice of signals, whereas those leading from the female nodes correspond to a female's choice of responses. When receiving an H- or an L-signal, a female would not be sure of where she is in the game tree, i.e. she would not know whether the male is a high-quality or a low-quality male. This imperfect information is indicated by the dashed lines between the female nodes. Although the female does not receive complete information about a male's quality, she would have some 'beliefs' about the probability that she finds herself at the upper or lower node $\left(\mu_{1}\right.$ or $\left.\mu_{2}\right)$. The probability that a male is of poor quality given H- and L-signal, is given by $\mu_{1}$ and $\mu_{2}$, respectively. The pay-offs are denoted in this way: (pay-off of male, pay-off of female). The pay-off combination associated with any choice pair appears at the ending branches of the tree. The pay-off elements in the game tree are defined as: pay-offs of mating with a high-quality and a low-quality male are given by $V$ and $v$, respectively. Pay-off of mating with a female of average quality is given by $W$. Let $c_{\text {time }}>0$ : the cost of time when the female mate choice is slightly delayed, is given by $c_{\text {time }}$. Let $C_{\mathrm{f}}>c_{\text {time }}$ : a female's cost of using time and energy on a male she later rejects is given by $C_{\mathrm{f}}$. Let $C_{\mathrm{m}}>0$ : a male's cost of being occupied for a period by a female is given by $C_{\mathrm{m}}$.

quality signal (L). The signals are equally costly. A male is of low quality with probability $p$, and of high quality with probability $1-p$. Females are selected to choose the expected optimal response after receiving a signal (H or L) from a male. Females can stay with the male $(\mathrm{S})$ or reject the male at once $(\mathrm{R})$. When a female receives $\mathrm{H}$, a third response is possible: accept the male but later divorce him if she realizes she has been cheated about his quality (D). All the possible outcomes and their pay-offs are given in figure 1. By 'pay-off', I mean the gain in fitness to an individual acquired by a particular signal or response.

A male's expected pay-off of mating with a female is the value of an average female, $W$. Encountering a female with strategy D, a male of low quality will later be left by the female and thus receive a negative pay-off due to the cost of being occupied for some period of time. There is no change in a male's fitness if the female chooses to reject him (the payoff is zero). Assume that females choose $\mathrm{H}$-signalling males in preference for L-signalling males. The payoff of a female who chooses to stay with a high-quality male is $V$, and a low-quality male $v$. If she rejects a male, she still has the chance to search for another one. Then, her pay-off is the expected value of the next $\mathrm{H}$-signalling male, which is dependent on the probability of this male being of high quality. However, the decision of rejecting a male and going for the next $\mathrm{H}$-signalling male instead implies a cost of time. Especially, this cost of time would be consider- able if there are few $\mathrm{H}$-signalling males in the area or they are hard to find. If a female is adopting strategy D and encounters a low-quality male, she will divorce him and search for a new mate. Her pay-off is the expected value of her next mate, but she also has to bear the cost of time and energy used on staying with the mate she left. This cost also includes the fact that some of the previously accessible males are likely to have been occupied by other females.

The strategies of males and females, respectively, are denoted in this way: $s_{\mathrm{m}}$ (male signal if of high quality, male signal if of low quality) and $s_{\mathrm{f}}$ (female response given $\mathrm{H}$-signal, female response given L-signal).

\section{(b) The existing ESSs}

There are three different strategies the males in a population may adopt. The males can be honest signalling, all the males can advertise that they are of high quality, or there can be a mixed strategy where some of the low-quality males are deceiving and signalling that they are of high quality. Basically, the procedure of finding the existing ESS solutions of the game consists of four points, as follows. (i) Select one of the possible male strategies and assume that all the males in the population are adopting this strategy. (ii) Given this male strategy, what is the optimal response of a female receiving an $\mathrm{H}$-signal? What is the optimal response of a female receiving an L-signal? (iii) For all the possible optimal female 


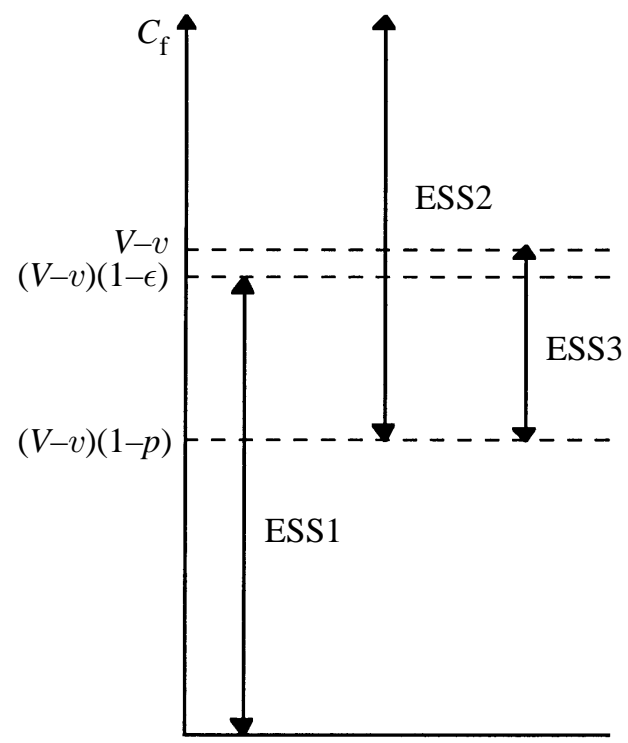

Figure 2. The range of $C_{\mathrm{f}}$-values (the female's cost of divorce) favouring the different stable strategies. At the ESS 1 the males are honestly signalling, at the ESS 2 all the males are advertising that they are of high quality, and at the ESS 3 males and females are adopting a mixed strategy. (See legend to figure 1 for definitions of the parameters.)

strategies, examine if the given male strategy is optimal. If neither males nor females could make it better (or as well as before) by changing their strategy we have got an ESS (Maynard Smith \& Price 1973; Maynard Smith 1982). (iv) Repeat the procedure for the other possible male strategies.

The procedure of finding a mixed ESS is somewhat different to the one above (see Appendix 1). The pay-offs of the different actions in a mixed ESS are frequency dependent and selection has acted to equalize those pay-offs (Maynard Smith 1982). In a mixed ESS the female response to a male H-signal cannot be $R$ because the female response $S$ would always be superior to $\mathrm{R}$ (see figure 1 ). Thus, in computing the mixed ESS, we have to find the frequency at which a low-quality male can cheat for the female to be indifferent between the responses $\mathrm{S}$ and D. Likewise, we have to find the frequency at which a female can adopt the strategy $\mathrm{S}$ in response to male H-signal for the low-quality male to be indifferent between signalling the H-signal and the L-signal.

In Appendices 1-3, I show that there are three possible ESS solutions to the game of signalling, as follows.

ESS 1: the ESS of honest signalling. $s_{\mathrm{m}}(\mathrm{H}, \mathrm{L})$ and $s_{\mathrm{f}}(\mathrm{D}, \mathrm{R})$ if the female's cost of divorce is not too great $\left(C_{\mathrm{f}}<(V-v)(1-\varepsilon)\right)$.

ESS 2: the ESS where all the males are advertising that they are of high quality. $s_{\mathrm{m}}(\mathrm{H}, \mathrm{H})$ and $s_{\mathrm{f}}(\mathrm{S}, \mathrm{R})$ if $C_{\mathrm{f}}>(1-p)(V-v)$ and if an L-signal is expected to be a signal from a male of low quality $\left(\mu_{2}<p+\right.$ $\left.c_{\text {time }} /(V-v)\right)$

ESS 3: the ESS of mixed strategies. $s_{\mathrm{m}}(\mathrm{H}, \mathrm{H}$ with probability $\phi)$ where $\phi=\left((V-v) / C_{\mathrm{f}}-1\right)(1-p) / p$, and $s_{\mathrm{f}}\left(\mathrm{S}\right.$ with probability $C_{\mathrm{m}} /\left(W+C_{\mathrm{m}}\right)$ else $\left.\mathrm{D}, \mathrm{R}\right)$ under the conditions: $(V-v)(1-p)<C_{\mathrm{f}}<(V-v)$ and the female's cost of slightly delaying the mate choice is small $\left(c_{\text {time }}>\left(1-\mu_{1}\right)(V-v)\right)$.

\section{RESULTS}

When males are adopting the strategy $s_{\mathrm{m}}(\mathrm{H}, \mathrm{L})$ they are honestly signalling their quality. The results show that honest and cheap signalling of quality is evolutionarily stable if females have the strategy $s_{\mathrm{f}}(\mathrm{D}, \mathrm{R})$, provided that the female's cost of divorcing a male is not too great (see figure 2) and that there are some males of high quality in the population. The gain in fitness of mating with a high-quality male compared to one of low quality must be greater than the decrease in fitness due to a divorce. If there is a small probability that the female would assess a male signal wrongly or that a low-quality male is signalling the H-signal he is not supposed to send, the female strategy D becomes a slightly better response than the strategy $\mathrm{S}$ given male $\mathrm{H}$-signal. In this ESS of honest signalling, the cost of divorce prevents lowquality males from deceiving and signalling that they are of high quality.

On the other hand, if the cost of time is so great that the female's cost of divorcing a male becomes considerable, the only possible ESS is one where all the males are advertising that they are of high quality, $s_{\mathrm{m}}(\mathrm{H}, \mathrm{H})$, i.e. there are no signals (see figure 2 ). The cost of divorce would be high when there are few males of high quality or when there is a shortage of $\mathrm{H}$-signalling males in the population and the female competition is strong. Then, a divorce would not give an opportunity for the female to obtain a new mate of higher quality. The female strategy $s_{\mathrm{f}}(\mathrm{S}, \mathrm{R})$ would seem like random mating as long as all the males are sending the H-signal. For this apparent 'random female mating' to be part of an ESS, an abnormal male sending the unexpected L-signal must be expected to be of low quality. Real random mating, i.e. $s_{\mathrm{f}}(\mathrm{S}, \mathrm{S})$, can only be part of a neutrally stable equilibrium and is not an ESS (Appendix 2).

The results of the game of signalling show that if the female cost of slightly delaying the mate choice is not too great $\left(c_{\text {time }}<\left(1-\mu_{1}\right)(V-v)\right)$, we also might predict an ESS in mixed strategies. In this mixed ESS, a small proportion $(\phi)$ of the low-quality males would cheat and signal that they are of high quality. However, for this ESS to apply, the possible range of the parameter $C_{\mathrm{f}}$, the cost of divorce for females, is quite restricted (see ESS 3 and figure 2). The restriction is dependent on the proportion of high-quality males in the population. As for ESS 2, the mixed ESS would be more likely if there are few males of high quality. The mixed ESS may be realized in two ways. There could be a polymorphism in the population with every individual playing a pure strategy with the frequencies of different behaviours corresponding to the ESS. Alternatively, each male and female could play the same mixed strategy. 


\section{DISCUSSION}

The female faces a trade-off between becoming more certain of the quality of a potential mate and the cost of gaining that information. Thus, a female may have to decide to mate with a particular male before she has sufficient information to assess his quality relative to other members of the mate pool (Sullivan 1994). The signalling system of the present divorce model is based on the assumption that the female may have the opportunity to divorce a mate which after continued assessment proves to be of poor quality. Divorce occurs in several monogamous species of animals (see, for example, Choudhury 1995; McNamara \& Forslund 1996). At least in birds, mating before the female is fertile, is the general rule (Birkhead \& Møller 1992), and hence the female has the option of switching mate before onset of egg-laying. If the chosen male proves to be of poor quality then he should be rejected, provided that the costs of doing so (in terms of lifetime reproductive success) do not outweigh the benefits (Lazarus 1990). Even if the female judges her mate to be of poorer than average quality, there are constraints on the female's freedom to divorce and switch partners. There would, for instance, be constraints on the time available for rearing offspring, and later in the season most of the males would already be paired (e.g. Sullivan 1994).

Contrary to Zahavi's handicap principle, honest signalling may be evolutionarily stable even when the signals involved are not handicaps for males of high quality. Producing the signal $\mathrm{H}$ may not necessarily be more costly than producing the signal L. Honest signalling $\left(s_{\mathrm{m}}(\mathrm{H}, \mathrm{L})\right)$ may be part of an ESS where females have the strategy $s_{\mathrm{f}}(\mathrm{D}, \mathrm{R})$. The signalling system of this model is very simple and obvious. The important point is that honest and cost-free signals may be maintained in the population because possible deceivers would be 'punished' by the receiver of the signal. Deceivers, i.e. males of low quality displaying H-signals, are prevented from spreading in the population because they would be abandoned by females and thus they would suffer from a cost of divorce. Honest signalling by males would at the same time reduce sampling costs in females.

The mechanism of the maintenance of honest signalling presented in this paper is somewhat similar to the one previously put forward in systems of aggressive interactions and signalling of intentions; i.e. dominance badge systems (Rohwer 1977; Enquist 1985; Møller 1987; Maynard Smith \& Harper 1988; see also Dawkins \& Guilford 1991). Signals of intention or status need not be inherently costly to produce, but costs may be imposed by the receivers of the signals. For example, an aggressive opponent might challenge the signaller to assess the reliability of the signal. The signaller would have to bear the costs of the conflict. Such costs may control the occurrence of cheating, and so provide evolutionary stability of a signalling system. However, according to the model of Johnstone \& Norris (1993), the stability of honest signalling in the badge of dominance game depends not only on the occurrence of social punishment, but also on the existence of a contestindependent cost to dominance. Conversely, in the divorce model, the stability depends only on females divorcing deceivers. One important feature of the divorce model is that costs are only imposed on signallers of low quality.

Costs to the signaller may be incurred in the production and maintenance of the signals, or costs may be imposed by target receivers themselves (Dawkins 1993; Guilford \& Dawkins 1995). Both kinds of costs are possible mechanisms to guarantee the honesty of signals in Grafen's (1990) model of the handicap principle (Guilford \& Dawkins 1995). Therefore, the ESS of cost-free and honest signalling obtained here is consistent with the model of Grafen, but not with the handicap principle of Zahavi. The handicap principle proposes that females prefer mates with handicaps (display characters that may reduce survival) because handicaps are indicators of the signaller's true quality. The divorce model shows that females may prefer to mate with high-signalling males even if there are no signalling costs to males of high quality. While the H-signals are cheap to produce, they would still incur socially imposed costs at the ESS of honest signalling, if used dishonestly by low-quality males.

Other models of 'cost-free' signalling than the one presented in this paper are based on quite different conditions for honest communication to be stable in a population. The condition in Krakauer \& Pagel's (1995) model for example, is spatial constraints. They show that cost is not a necessary condition for the maintenance of honest signalling if individuals are spatially constrained in their choice of interactant. Honest signalling without costs of any kind has previously been obtained in non-spatial situations, but they depend upon interactants being related (Johnstone \& Grafen 1992a; Maynard Smith $1991,1994)$. The mutual interests of the related interactants should guarantee that the cheap signals will only rarely be misused.

In the divorce model, low-quality males do not obtain any mates at the ESS of honest signalling. The signalling of low-quality males might therefore seem like a paradox. However, male honest signalling and female rejection of low-quality males is no longer an ESS if the female's cost of divorce becomes very high or if all the males of high quality are already mated. In such cases, the optimal female strategy is to stay with the male no matter what signal he is sending. Thus, especially late in the mating season, males of low quality indeed have a chance to become mated. It has been shown that females are less selective late in the season (Johnsen \& Zuk 1996) and when the realized frequency of unmated males becomes low (Dale et al. 1992).

If the cost of divorce increases over the course of the breeding season, or if the benefits decrease (because high-quality males are running out), dishonesty becomes increasingly likely according to the divorce model (see figure 2). Accordingly, we might predict 
male display to be more informative early in the season when the threat of divorce is greater.

Dishonest signals can be stable and persist in a population only if they have a frequency-dependent advantage (Dawkins \& Guilford 1991; Johnstone \& Grafen 1993). Given an element of receiver uncertainty, cheating may be part of a stable signalling system if its incidence is low enough (Johnstone \& Grafen 1993). When the link between a signal and the signaller's quality is less than perfect, the receiver does not know the precise state of the signaller and must therefore react according to the average state of signallers (Dawkins \& Guilford 1991; Johnstone \& Grafen 1993; Maynard Smith 1994).

In handicap models of signalling, receiver uncertainty may be introduced if the signallers vary both in their ability to pay the cost of signalling and in the amount they stand to gain (Johnstone \& Grafen 1993). Similarly, receiver uncertainty may arise from perceptual error (i.e. signals are not detected with perfect reliability and assessed with perfect accuracy) (Johnstone \& Grafen 1992b; Johnstone 1994). If there is an asymmetry of costs and benefits between signallers, this would be reflected in the intensity of their signals. Receivers may therefore encounter a highly expressed handicap presented by a poor quality signaller, and in the eyes of the receiver, this would be a cheat (Hasson 1994). In the divorce model, individuals of the same quality may adopt different strategies, although their costs and benefits of signalling are the same. Here cheating means that an individual of low quality is dishonestly signalling that he is of high quality. The receiver's uncertainty arises because there is no necessary correlation between a signaller's quality and the level of signalling; the H-signal is no more costly to produce than the L-signal.

The spatial game theory model of Krakauer \& Pagel (1995) showed that honesty and dishonesty may coexist as a mixed polymorphism in a population. This feature is not unique to spatial models. Under some relatively strict conditions, a mixed polymorphism of dishonesty and honesty is also a result of the divorce model. In the mixed ESS, a small proportion of the low-quality individuals in the population is dishonestly signalling that they are of high quality. At the ESS of honest signalling all the males are honest, and we would not expect to observe any divorces in the population. Still, when divorces occur in nature, they are not contradicting my model. Although if the whole population is at equilibrium, it is a possibility that it is adopting the alternative ESS of mixed strategies.

With signals which do not advertise quality directly, there would be many possible systems equally capable of carrying the same messages, and selection for efficiency and historical contingency should have great effect on the signal design (Guilford \& Dawkins 1991, 1995; Dawkins 1993). The distinction between signals that are inherently costly to produce and those that are not, might lead to testable predictions. However, few experimental studies have been able to assess the costs of display properly (but see, for example, Evans \& Thomas 1992; Borgia 1993; Møller \& de Lope 1994). The fact that it is possible to demonstrate that signals are costly to produce does not mean that the signals are costly enough to be considered as necessary correlates of some underlying quality (Dawkins \& Guilford 1991; Borgia 1993; Johnstone 1995).

At the ESS of honest signalling in the divorce model, the signalling system is reliable, i.e. no male of poor quality would display the high-quality signal because of the cost involved in divorce. Then, there is no reason for females to prefer more costly signals, and obviously, the cheap signals are an advantage for the males. A more costly signal does not necessarily mean that the system of signalling is more reliable. I suggest that cheap signals might be common, at least in connection with mate choice but also in connection with choice of partner in other systems of co-operation.

This work was a part of my Cand. Scient. thesis in zoology at the University of Oslo. I greatly appreciate the support from my supervisors Nils Chr. Stenseth and Tore Slagsvold. I also wish to thank Trond Amundsen, Kjell Arne Brekke, Thomas F. Hansen and Glenn-Peter Sætre for many helpful comments and suggestions on drafts of this article.

\section{APPENDIX 1. LOOKING FOR A MIXED ESS}

Suppose males are adopting the strategy $s_{\mathrm{m}}(\mathrm{H}, \mathrm{H}$ with probability $\phi)$, where $\phi \in\langle 0,1\rangle$. Suppose further that a female given $\mathrm{H}$-signal chooses $\mathrm{S}$ with probability $\alpha$ and $\mathrm{D}$ with probability $1-\alpha$, and that a female given L-signal chooses $\mathrm{R}$ with probability one. Given male H-signal, note that because of the cost of time, the female response $\mathrm{S}$ is always superior to R. From Bayes's rule we can find the probability that a male is of high quality given $\mathrm{H}$-signal:

$$
\begin{aligned}
1-\mu_{1} & =\operatorname{Pr}(\text { high quality } \mid \mathrm{H}) \\
& =(1-p) /((1-p)+p \phi) .
\end{aligned}
$$

A female is indifferent between $\mathrm{S}$ and $\mathrm{D}$ given $\mathrm{H}-$ signal if $\phi=\left((V-v) / C_{\mathrm{f}}-1\right)(1-p) / p$. To fulfil the conditions $\phi \in\langle 0,1\rangle, C_{\mathrm{f}}$ has to be a number between $(1-p)(V-v)$ and $(V-v)$.

$\mathrm{R}$ is the optimal response of a female given L-signal if the probability to obtain a mate of high quality after rejecting a male outweigh the cost of the slight delay in the mate choice process, i.e.

$$
\begin{aligned}
c_{\text {time }} & <\left(1-\mu_{1}\right)(V-v) \\
& =(V-v)(1-p) /((1-p)+p \phi) .
\end{aligned}
$$

A low-quality male is indifferent between $\mathrm{H}$ and $\mathrm{L}$ whenever $\alpha=C_{\mathrm{m}} /\left(W+C_{\mathrm{m}}\right)$.

Thus, under the conditions $(V-v)(1-p)<C_{\mathrm{f}}<$ $(V-v)$ and $c_{\text {time }}<\left(1-\mu_{1}\right)(V-v)$, there is an ESS of mixed strategies: $s_{\mathrm{m}}(\mathrm{H}, \mathrm{H}$ with probability $\phi)$ where $\phi=\left((V-v) / C_{\mathrm{f}}-1\right)(1-p) / p$, and $s_{\mathrm{f}}(\mathrm{S}$ with probability $C_{\mathrm{m}} /\left(W+C_{\mathrm{m}}\right)$ else $\left.\mathrm{D}, \mathrm{R}\right)$. 


\section{APPENDIX 2. LOOKING FOR ESS WHERE ALL THE MALES ARE SENDING THE H-SIGNAL}

Suppose males adopt the strategy $s_{\mathrm{m}}(\mathrm{H}, \mathrm{H})$. When males are only sending the H-signal, a male's signal will not give any clue to females about his real quality. Thus, $\mu_{1}=p$ (Bayes's rule).

The optimal response of a female given a male $\mathrm{H}-$ signal (see figure 1): the response $\mathrm{S}$ is always superior to $\mathrm{R}, \mathrm{S}$ is optimal if $C_{\mathrm{f}}>(1-p)(V-v)$, and $\mathrm{D}$ is optimal if $C_{\mathrm{f}}<(1-p)(V-v)$.

To find a possible ESS, we also have to specify what a female will choose given an L-signal. L-signals are not sent with a positive probability. Bayes's rule therefore, will not apply and the female may assign any probability for the male to be of poor quality (e.g. Kreps 1990). $\mathrm{R}$ is the optimal response when $\mu_{2}>p+c_{\text {time }} /(V-v)$.

$s_{\mathrm{f}}(\mathrm{D}, \mathrm{S})$ or $s_{\mathrm{f}}(\mathrm{D}, \mathrm{R})$ cannot be part of an ESS with the male strategy $s_{\mathrm{m}}(\mathrm{H}, \mathrm{H})$ because the pay-off of a low-quality male is $-C_{\mathrm{m}}$, and he would do better by sending the signal $\mathrm{L}$.

$s_{\mathrm{f}}(\mathrm{S}, \mathrm{R})$ would be part of an ESS if the female's cost of divorce is considerable $\left(C_{\mathrm{f}}>(1-p)(V-v)\right)$, and if an L-signal is expected to be a signal from a male of low quality $\left(\mu_{2}>p+c_{\text {time }} /(V-v)\right)$, then neither the female nor the male could make it better (or as well as before) by changing their strategies.

If the female cost of divorce is considerable but an L-signal is expected to be a signal from a male of high quality $\left(\mu_{2}<p+c_{\text {time }} /(V-v)\right)$, the female strategy $s_{\mathrm{f}}(\mathrm{S}, \mathrm{S})$ might be part of an equilibrium. However, this equilibrium would only be neutrally stable, because the males could do equally well by sending the L-signal instead of the H-signal. Thus, the only possible ESS is $s_{\mathrm{m}}(\mathrm{H}, \mathrm{H})$ and $s_{\mathrm{f}}(\mathrm{S}, \mathrm{R})$.

\section{APPENDIX 3. LOOKING FOR ESS WHERE MALES ARE HONEST SIGNALLING}

Suppose males adopt the strategy $s_{\mathrm{m}}(\mathrm{H}, \mathrm{L})$, i.e. the males are honestly signalling their quality. There is a possibility that the female occasionally would assess a male signal wrongly or that a low-quality male is signalling the H-signal he is not supposed to advertise. With this kind of 'noise' (denoted $\varepsilon$ below), a female cannot be absolutely sure that the male really is of high quality when she receives a male $\mathrm{H}$ signal. In other words, the female cannot know for sure where she is in the game tree; $1-\mu_{1}=1-\varepsilon$ and $\mu_{2}=1-\varepsilon$ (see figure 1$)$.

Given male H-signal, a female's pay-off of choosing $\mathrm{S}, \mathrm{D}$ and $\mathrm{R}$ is (see figure 1 )

$$
\begin{aligned}
u(\mathrm{~S}) & =(1-\varepsilon) V+\varepsilon v, \\
u(\mathrm{D}) & =(1-\varepsilon) V+\varepsilon\left((1-\varepsilon) V+\varepsilon v-C_{\mathrm{f}}\right), \quad \text { and } \\
u(\mathrm{R}) & =(1-\varepsilon) V+\varepsilon v-c_{\text {time }} .
\end{aligned}
$$

The female response $\mathrm{S}$ is always superior to $\mathrm{R}$. The female response $\mathrm{D}$ is a better response than $\mathrm{S}$ if $C_{\mathrm{f}}<$ $(1-\varepsilon)(V-v)$. As long as there is some chance that an H-signalling male is not a male of high quality and the female's cost of divorce is not too great, D would be the only optimal female response to a male H-signal.

Given male L-signal, $\mathrm{R}$ is the optimal female choice if $c_{\text {time }}<(1-\varepsilon)(V-v)$ (see figure 1$)$, that is, the cost of slightly delaying the mate choice is not too great.

If females adopt the strategy $s_{\mathrm{f}}(\mathrm{S}, \mathrm{R})$, we would not have an ESS, because low-quality males will make it better if they deceive and choose the signal $\mathrm{H}$. If the female's cost of slightly delaying the mate choice is considerable, it is optimal for the female to stay with the male. However, if the female strategy is $s_{\mathrm{f}}(\mathrm{S}, \mathrm{S})$, honest signalling would only be neutrally stable for the males. A male of low quality would do no worse cheating and advertising that he is of high quality. For honest signalling to be an ESS, there must be a reason why the signal $\mathrm{L}$ is a better choice than $\mathrm{H}$ for a low-quality male (Maynard Smith \& Price 1973; Maynard Smith 1982).

If the females adopt the strategy $s_{\mathrm{f}}(\mathrm{D}, \mathrm{R})$ and the female's cost of divorce is not too great, we would have an ESS of male honest signalling. Neither males nor females could make it better by changing their strategies.

\section{REFERENCES}

Andersson, M. 1994 Sexual selection. Princeton, NJ: Princeton University Press.

Birkhead, T. R. \& Møller, A. P. 1992 Sperm competition in birds: evolutionary causes and consequences. London: Academic.

Borgia, G. 1993 The cost of display in the non-resourcebased mating system of the satin bowerbird. Am. Nat. 141, 729-743.

Choudhury, S. 1995 Divorce in birds: a review of the hypotheses. Anim. Behav. 50, 413-429.

Dale, S., Rinden, H. \& Slagsvold, T. 1992 Competition for a mate restricts mate search of female pied flycatchers. Behav. Ecol. Sociobiol. 30, 165-176.

Dawkins, M. S. 1993 Are there general principles of signal design? Phil. Trans. R. Soc. Lond. B 340, 251-255.

Dawkins, M. S. \& Guilford, T. 1991 The corruption of honest signalling. Anim. Behav. 41, 865-873.

Enquist, M. 1985 Communication during aggressive interactions with particular reference to variation in choice of behaviour. Anim. Behav. 33, 1152-1161.

Evans, M. R. \& Thomas, A. L. R. 1992 The aerodynamic and mechanical effects of elongated tails in the scarlettufted malachite sunbird: measuring the cost of a handicap. Anim. Behav. 43, 337-347.

Godfray, H. C. J. 1991 Signalling of need by offspring to their parents. Nature 352, 328-330.

Godfray, H. C. J. 1995 Communication between the first and third trophic levels: an analysis using biological signalling theory. Oikos 72, 367-374.

Grafen, A. 1990 Biological signals as handicaps. J. Theor. Biol. 144, 517-546.

Guilford, T. \& Dawkins, M. S. 1991 Receiver psychology and the evolution of animal signals. Anim. Behav. 42, $1-14$.

Guilford, T. \& Dawkins, M. S. 1995 What are conventional signals? Anim. Behav. 49, 1689-1695.

Hasson, O. 1994 Cheating signals. J. Theor. Biol. 167, 223-238. 
Janetos, A. C. 1980 Strategies of female mate choice: a theoretical analysis. Behav. Ecol. Sociobiol. 7, 107-112.

Johnsen, T. S. \& Zuk, M. 1996 Repeatability of mate choice in female red jungle fowl. Behav. Ecol. 7, 243246.

Johnstone, R. A. 1994 Honest signalling, perceptual error and the evolution of 'all-or-nothing' displays. Proc. $R$. Soc. Lond. B 256, 169-175.

Johnstone, R. A. 1995 Sexual selection, honest advertisement and the handicap principle: reviewing the evidence. Biol. Rev. 70, 1-65.

Johnstone, R. A. \& Grafen, A. 1992a The continuous Sir Philip Sidney game: a simple model of biological signalling. J. Theor. Biol. 156, 215-234.

Johnstone, R. A. \& Grafen, A. $1992 b$ Error-prone signalling. Proc. R. Soc. Lond. B 248, 229-233.

Johnstone, R. A. \& Grafen, A. 1993 Dishonesty and the handicap principle. Anim. Behav. 46, 759-764.

Johnstone, R. A. \& Norris, K. 1993 Badges of status and the cost of aggression. Behav. Ecol. Sociobiol. 32, 127134 .

Krakauer, D. C. \& Pagel, M. 1995 Spatial structure and the evolution of honest cost-free signalling. Proc. $R$. Soc. Lond. B 260, 365-372.

Kreps, D. M. 1990 A course in microeconomic theory. Princeton, NJ: Princeton University Press.

Lazarus, J. 1990 The logic of mate desertion. Anim. Behav. 39, 672-684.

Maynard Smith, J. 1982 Evolution and the theory of games. Cambridge University Press.

Maynard Smith, J. 1991 Honest signalling: the Philip Sidney game. Anim. Behav. 42, 1034-1035.

Maynard Smith, J. 1994 Must reliable signals always be costly? Anim. Behav. 47, 1115-1120.

Maynard Smith, J. \& Harper, D. G. C. 1988 The evolution of aggression: can selection generate variability? Phil. Trans. R. Soc. Lond. B 319, 557-570.

Maynard Smith, J. \& Price, G. R. 1973 The logic of animal conflict. Nature 246, 15-18.

McNamara, J. M. \& Forslund, P. 1996 Divorce rates in birds: predictions from an optimization model. Am. Nat. 147, 609-640.
Møller, A. P. 1987 Social control of deception among status signalling house sparrows Passer domesticus. Behav. Ecol. Sociobiol. 20, 307-311.

Møller, A. P. \& de Lope, F. 1994 Differential costs of a secondary sexual character: an experimental test of the handicap principle. Evolution 48, 1676-1683.

Pagel, M. 1993 Honest signalling among gametes. Nature 363, 539-541.

Parker, G. A. 1983 Mate quality and mating decisions. In Mate choice (ed. P. Bateson), pp. 141-166. Cambridge University Press.

Pomiankowsky, A. $1987 a$ The cost of choice in sexual selection. J. Theor. Biol. 128, 195-218.

Pomiankowsky, A. $1987 b$ Sexual selection: the handicap principle does work-sometimes. Proc. R. Soc. Lond. B 231, 123-145.

Rohwer, S. 1977 Status signalling in harris sparrows: some experiments in deception. Behaviour 61, 107129.

Sullivan, M. S. 1994 Mate choice as an information gathering process under time constraint: implications for behaviour and signal design. Anim. Behav. 47, 141151.

Vega-Redondo, F. \& Hasson, O. 1993 A game-theoretic model of predator-prey signalling. J. Theor. Biol. 162, 309-319.

Wedekind, C. 1994 Handicaps not obligatory in sexual selection for resistance genes. J. Theor. Biol. 170, 5762.

Yachi, S. 1995 How can honest signalling evolve? The role of the handicap principle. Proc. R. Soc. Lond. B 262, 283-288.

Zahavi, A. 1975 Mate selection-a selection for a handicap. J. Theor. Biol. 53, 205-214.

Zahavi, A. 1977 The cost of honesty (further remarks on the handicap principle). J. Theor. Biol. 67, 603-605.

Zahavi, A. 1987 The theory of signal selection and some of its implications. In International symposium of biological evolution (ed. V. P. Delfino), pp. 305-327. Bari: Adriatica Editrica.

Received 23 January 1997; accepted 19 February 1997 